\title{
Impacto de silicato de potássio no desenvolvimento do tomateiro
}

\section{Luís Eduardo Silva Faleiro', Carlos Augusto Faleiro Abreu$^{1}$, Aurivan Soares de Freitas ${ }^{1}$,*, Maria Gilmara de Oliveira Soares ${ }^{2}$, Alisson Souza de Oliveira ${ }^{1}$ e Ramiro Machado Rezende ${ }^{1}$}

\author{
${ }^{1}$ Universidade Vale do Rio Verde. Campus Três Corações. Av. Castelo Branco, 82. \\ Chácara das Rosas. Três Corações-MG, Brasil (CEP 37410-000). E-mail: \\ aurivan.soares@hotmail.com. \\ ${ }^{2}$ Universidade Federal de Lavras. Caixa Postal 3037. Lavras-MG, Brasil (CEP \\ 37200-900).
}

Resumo. 0 tomate é uma hortaliça consumida mundialmente, sendo assim, tem forte importância social, econômica e alimentar. $\mathrm{Na}$ produção desta hortaliça, tem sido aplicado silício (Si), visando ao controle de insetos-praga, patógenos e ao aumento na produção. 0 fornecimento deste elemento pode reduzir a aplicação de produtos sintéticos e assim diminuir a poluição ambiental. Sendo assim, no presente trabalho avaliou-se o efeito da adubação foliar com silicato de potássio no desenvolvimento do tomateiro. Os tratamentos foram compostos por cinco concentrações de silicato de potássio. As concentrações foram compostas por $0,250,500,750,1.000 \mathrm{~mL}$ de silicato de potássio 100. $\mathrm{L}^{-1}$. Aos 35 dias após o transplante foram avaliados diâmetro do colo, altura de plantas e número de folhas. 0 desenvolvimento do tomateiro sofreu influência do suprimento foliar de silicato de potássio. 0 aumento das concentrações de silicato de potássio, via foliar, influenciou significativamente o diâmetro do colo, altura de plantas e número de folhas. Com o aumento das concentrações de silicato de potássio de 0 para $850,5 \mathrm{~mL} .100 \mathrm{~L}^{-1}$ houve aumento do diâmetro do colo de 1,031 para $1,14 \mathrm{~mm}$, respectivamente. Da mesma forma, a altura de plantas e o número de folhas variaram de 67,23 para $74,62 \mathrm{~cm}$ e de 15 para 18 folhas, respectivamente, com o aumento das concentrações do produto de 0 para 830,3 e

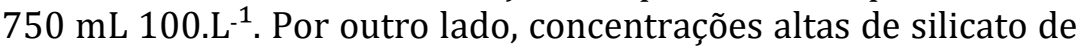
potássio resultaram em redução nos valores de diâmetro do colo, altura de plantas e número de folhas. Portanto, a adubação foliar de silicato de potássio melhora o desenvolvimento do tomateiro e poderá contribuir na redução da aplicação de produtos sintéticos.

Palavras-chave: Solanum lycopersicum L.; Silício; Diâmetro do colo; Altura de plantas.
Recebido

$22 / 05 / 2021$

Aceito

$27 / 11 / 2021$

Disponível on line

$28 / 11 / 2021$

Publicado

$31 / 12 / 2021$

Acesso aberto

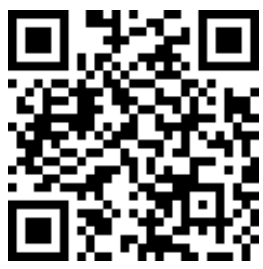

0000-0001-8508-2065

Luís Eduardo Silva

Faleiro

ISSN 2359-1412/RBGAS-2021-0055/2021/8/20/9/1399

Rev. Bras. Gest. Amb. Sustent.

http://revista.ecogestaobrasil.net 
Abstract. Impact of potassium silicate on tomato development. Tomato is a vegetable consumed worldwide, so it has a strong social, economic and food importance. In the production of this vegetable, silicon has been applied in order to control insect pests, pathogens and increase production. The supply of this element can reduce the application of synthetic products and thus reduce environmental pollution. Therefore, in the present work, the effect of foliar fertilization with potassium silicate on tomato development was evaluated. The treatments consisted of five concentrations of potassium silicate. The concentrations were composed of $0,250,500,750,1,000 \mathrm{~mL}$ of potassium silicate $100 \mathrm{~L}^{-1}$. At 35 days after transplantation, neck diameter, plant height and number of leaves were evaluated. Tomato development was influenced by the foliar potassium silicate supply. The increase in potassium silicate concentrations, via leaf, significantly influenced the diameter of the stem, plant height and number of leaves. With the increase in potassium silicate concentrations from 0 to $850.5 \mathrm{~mL} .100 \mathrm{~L}^{-1}$, there was an increase in the neck diameter from 1.031 to $1.14 \mathrm{~mm}$, respectively. Likewise, the height of plants and the number of leaves varied from 67.23 to $74.62 \mathrm{~cm}$ and from 15 to 18 leaves, respectively, with an increase in product concentrations from 0 to 830.3 and $750 \mathrm{~mL} .100 \mathrm{~L}^{-1}$. On the other hand, high concentrations of potassium silicate resulted in a reduction in the values of stem diameter, plant height and number of leaves. Therefore, foliar fertilization of potassium silicate improves tomato development and may contribute to reducing the application of synthetic products.

Keywords: Solanum lycopersicum L.; Silicon; Neck diameter; Plant height.

\section{Introdução}

O tomateiro Solanum lycopersicum L. é a segunda hortaliça mais consumida mundialmente, perdendo apenas para à batata (Nick et al. 2018). Em 2019, dados revelaram que foram produzidas aproximadamente 180 milhões de toneladas em uma área de 5 milhões de hectares. Nesse mesmo ano, o maior produtor foi a China com 62 milhões de toneladas e o Brasil ficou na décima colocação com quase 4 milhões de toneladas (FAO, 2021). Segundo dados do IBGE (2021), em 2020 os estados brasileiros maiores de tomate foram Goiás, São Paulo e Minas Gerais com 1.059.871 t, 1.026.300 t e $518.243 \mathrm{t}$, respectivamente.

Para garantir e aumentar esta produção sem expandir em área agricultável é comum a aplicação de agrotóxicos e fertilizantes sintéticos. Todavia, o uso desordenado destes produtos pode acarretar contaminação humana, animal e ambiental. Visando contornar estes entraves, o fornecimento de silício (Si) tem sido proposto como uma medida promissora. $\mathrm{O} \mathrm{Si}$ não é considerado elemento um essencial para $\mathrm{o}$ desenvolvimento das plantas, ou seja, na sua ausência estas conseguem completar seu desenvolvimento. Entretanto, diversos estudos têm demonstrado que o fornecimento de Si proporciona maior resistência a estresses bióticos e abióticos (Marschner, 2012; Pozza et al., 2015; Freitas et al., 2017). Além disso, o Si é o segundo elemento mineral mais 
abundante na natureza, representando aproximadamente, $28 \%$ da crosta terrestre (Epstein, 1994; Datnoff et al., 2007).

Alguns estudos confirmaram os efeitos benéficos do silício no desenvolvimento do tomateiro. Em ambiente protegido, a aplicação de silicato de potássio $\left(\mathrm{K}_{2} \mathrm{SiO}_{3}\right)$ em plantas de sob estresse hídrico apresentou efeito significativo na redução dos efeitos ocasionados pelo estresse hídrico (Nunes et al., 2019). Em outro estudo, envolvendo esta mesma formulação de $\mathrm{Si}$, houve incrementos na produtividade sendo que a dose de $0,38 \mathrm{~L} .100 \mathrm{~L}^{-1}$ proporcionou a máxima produção de frutos e a dose $0,33 \mathrm{~L} .100 \mathrm{~L}^{-1}$ de frutos totais (Rodrigues et al., 2016). Em relação ao desenvolvimento das plantas, um estudo comprovou que as variáveis altura da planta e peso fresco das raízes, apresentaram melhores resultados quando aplicada a dosagem de $25 \mathrm{~mL} \cdot \mathrm{L}^{-1}$ de $\mathrm{K}_{2} \mathrm{SiO}_{3}$. Enquanto para o número de folhas e de flores a concentração de $75 \mathrm{~mL} \cdot \mathrm{L}^{-1}$ favoreceu o aumento das médias (Rodrigues et al., 2016). No que diz respeito aos problemas fitossanitários, a aplicação de silício reduziu a intensidade de bactérias como Pseudomonas syringae pv. tomato (Andrade et al., 2013), Xanthomonas euvesicatoria, X. vesicatoria, X. gardneri e X. perforans (Anjos et al., 2014). Já para os insetos-praga, resultados demonstraram claramente que aplicações de silício diminuíram significativamente a população de imaturos de Bemisia tabaci Gennadius (Hemiptera: Aleyrodidae) e Tuta absoluta Meyrick (Lepidoptera: Gelechiidae) nas folhas de tomateiro em casa de vegetação (Alyousuf et al., 2021).

Dessa forma, objetivou-se com este trabalho avaliar o desenvolvimento do tomateiro em razão da aplicação foliar de silicato de potássio.

\section{Material e métodos}

O experimento foi realizado no povoado de Aguadinha, localizado na zona rural do Município de Passa Tempo, Estado de Minas Gerais, cujas coordenadas geográficas são $18^{\circ} 50^{\prime} 17^{\prime \prime}$ de latitude $S$ e $44^{\circ} 35^{\prime} 02^{\prime \prime}$ de longitude 0 .

Utilizou-se a cultivar Caeté (Blueseeds ${ }^{\circledR}$ ), hábito de crescimento determinado, com tolerâncias à Verticillium raça 1, Fusarium raças 1 e 2, Tobacco mosaic virus, Tomato spotted wilt virus e Tomato yellow leaf curl virus. As mudas foram produzidas em bandejas de plástico de 128 células em condições de ambiente protegido. 0 transplante foi realizado quando as mudas atingiram quatro folhas definitivas. Adotou-se um espaçamento de $1,35 \mathrm{~m}$ entre linhas e $40 \mathrm{~cm}$ entre plantas. As plantas foram tutoradas com fitilho e conduzidas com uma haste/planta.

Os tratos culturais como controle de plantas daninhas, insetos-praga, doenças, irrigação, amontoa foram realizados conforme recomendação para a cultura (Nick et al., 2018).

O experimento foi conduzido em delineamento em blocos casualizados (DBC) composto por cinco tratamentos e quatro parcelas. Os tratamentos foram compostos por cinco concentrações de silicato de potássio, Supa Sílica $\left(23,7 \% \mathrm{~K}_{2} \mathrm{O}+10 \% \mathrm{Si}\right)$ adquirido da Agrichem $^{\circledR}$. As concentrações testadas foram 0, 250, 500, 750, $1.000 \mathrm{~mL}$ de silicato de potássio $100 \mathrm{~L}^{-1}$. Foram realizadas duas aplicações aos sete e 15 dias após o transplante, até o ponto de escorrimento foliar. Cada parcela experimental foi constituída por 104 plantas, totalizando-se 2.080 plantas, distribuídas em 20 linhas, respeitando-se o espaçamento proposto anteriormente. Considerou-se como área útil as seis plantas centrais.

Aos 35 dias após o transplante foram avaliados diâmetro do colo (mm), altura de plantas e número de folhas. A altura de plantas foi mensurada em centímetros, a partir do colo das plantas até a gema apical, sendo os resultados expressos em centímetros. 0 número de folhas foi realizado pela contagem direta do número total de folhas por planta. 0 diâmetro do caule foi determinado medindo o colo da planta com paquímetro, em milímetros. 
As variáveis foram submetidas à análise de variância (ANOVA). As variáveis significativas foram submetidas ao ajuste de modelos de regressão, a $5 \%$ de probabilidade. As análises foram realizadas, utilizando-se o Software Sisvar (Ferreira, 2011).

\section{Resultados e discussão}

O desenvolvimento do tomateiro sofreu influência do suprimento foliar de silicato de potássio. $\mathrm{O}$ aumento das concentrações de silicato de potássio, via foliar, influenciou significativamente o diâmetro do colo, altura de plantas e número de folhas. Em relação ao diâmetro do colo, com o incremento das concentrações de silicato de potássio de 0 para

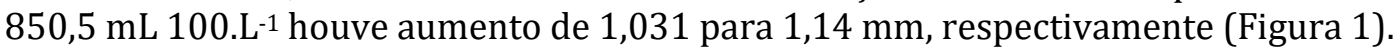

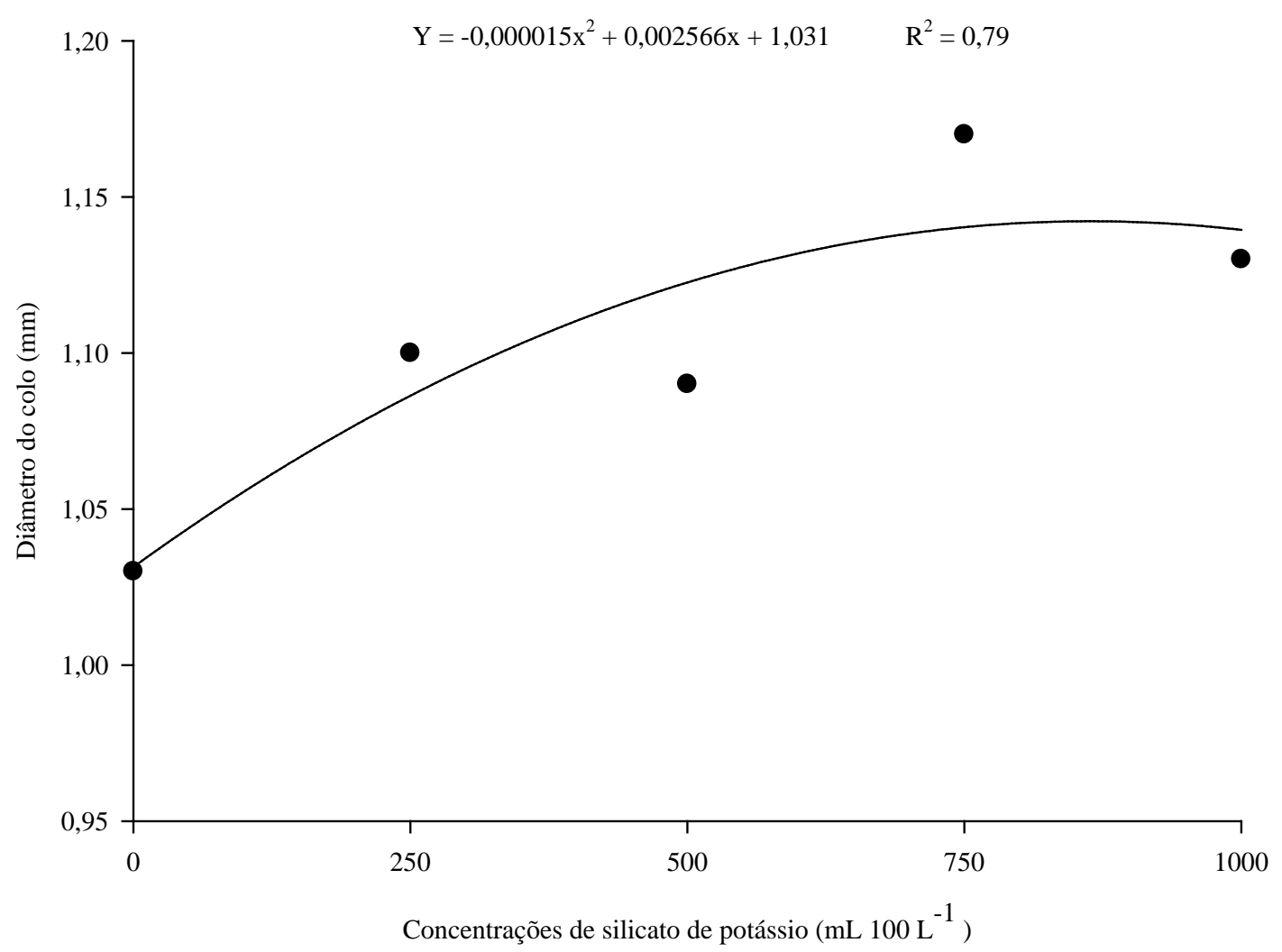

Figura 1. Diâmetro do colo do tomateiro, aos 35 dias após o transplante, em razão da aplicação foliar de silicato de potássio.

O diâmetro do colo é uma característica importante para o desenvolvimento das plantas, assim, o aumento no seu valor, normalmente, resulta em plantas com maior vigor. Nunes et al. (2019) constataram que o silicato de potássio nas concentrações de 25 e $50 \mathrm{~mL}^{\mathrm{L}} \mathrm{L}^{-1}$ influenciou significativamente o aumento no diâmetro do colo de tomateiro. De acordo com os autores, estes resultados ocorreram devido a deposição dos fotoassimilados influenciado pelo silício. Para outras culturas, constatou-se aumento no diâmetro do colo com fornecimento de Si, incluindo milho (Neri et al., 2009), roseiras (Ehret et al., 2005) e girassol (Kamenidou e Cavins, 2008). 
A altura de plantas é outro fator importante para o desenvolvimento de plantas. Para esta variável, o incremento de silicato de potássio de 0 para $830,3 \mathrm{~mL} .100 \mathrm{~L}^{-1}$ levou ao aumento de 67,23 para 74,62 cm, respectivamente (Figura 2). Resultados semelhantes foram evidenciados Nunes et al. (2019) para esta cultura. Segundo os autores aos 35 dias após o transplante, a concentração de $50 \mathrm{~mL} \cdot \mathrm{L}^{-1}$ de $\mathrm{K}_{2} \mathrm{SiO}_{3}$ proporcionou o maior crescimento das plantas, atingindo a altura média de $45,4 \mathrm{~cm}$, opondo-se a 42 e $38,8 \mathrm{~cm}$ encontrados na testemunha e $100 \mathrm{~mL} \cdot \mathrm{L}^{-1}$, respectivamente.

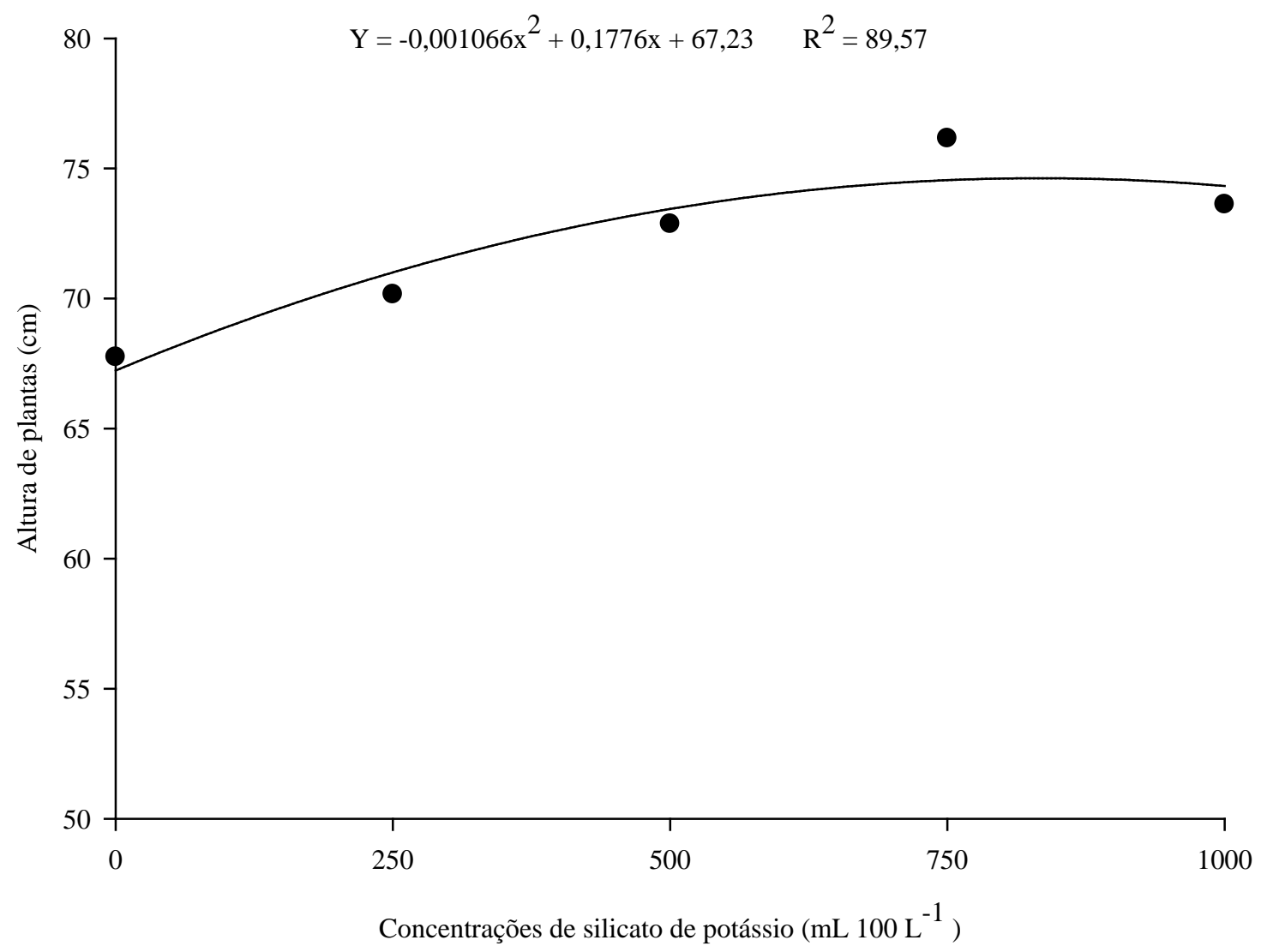

Figura 2. Altura de plantas de tomateiro, aos 35 dias após o transplante, em razão da aplicação foliar de silicato de potássio.

0 número de folhas variou de15 para 18 folhas, com o incremento de silicato de potássio de 0 para $750 \mathrm{~mL} .100 \mathrm{~L}^{-1}$, respectivamente (Figura 3).Rodrigues et al. (2018) observaram que o aumento na concentração de silicato de potássio foi diretamente proporcional ao número de folhas, exceto, para dose maior $\left(100 \mathrm{~mL} . \mathrm{L}^{-1}\right)$ de silicato de potássio. Em outro estudo com tomateiro, observou-se que o número de folhas tratadas com concentrações de 25 e $50 \mathrm{~mL} \cdot \mathrm{L}^{-1}$ de silicato de potássio foi superior à testemunha (Nunes et al., 2019). Zanão Júnior et al. (2013) evidenciaram que a aplicação de silício promoveu o aumento do número de folhas de roseiras. Dessa forma, fica evidente a importância do Si na atividade fotossintética da planta, conforme relata Pereira et al. (2003), este elemento pode favorecer a fotossíntese ao proporcionar folhas mais eretas. 


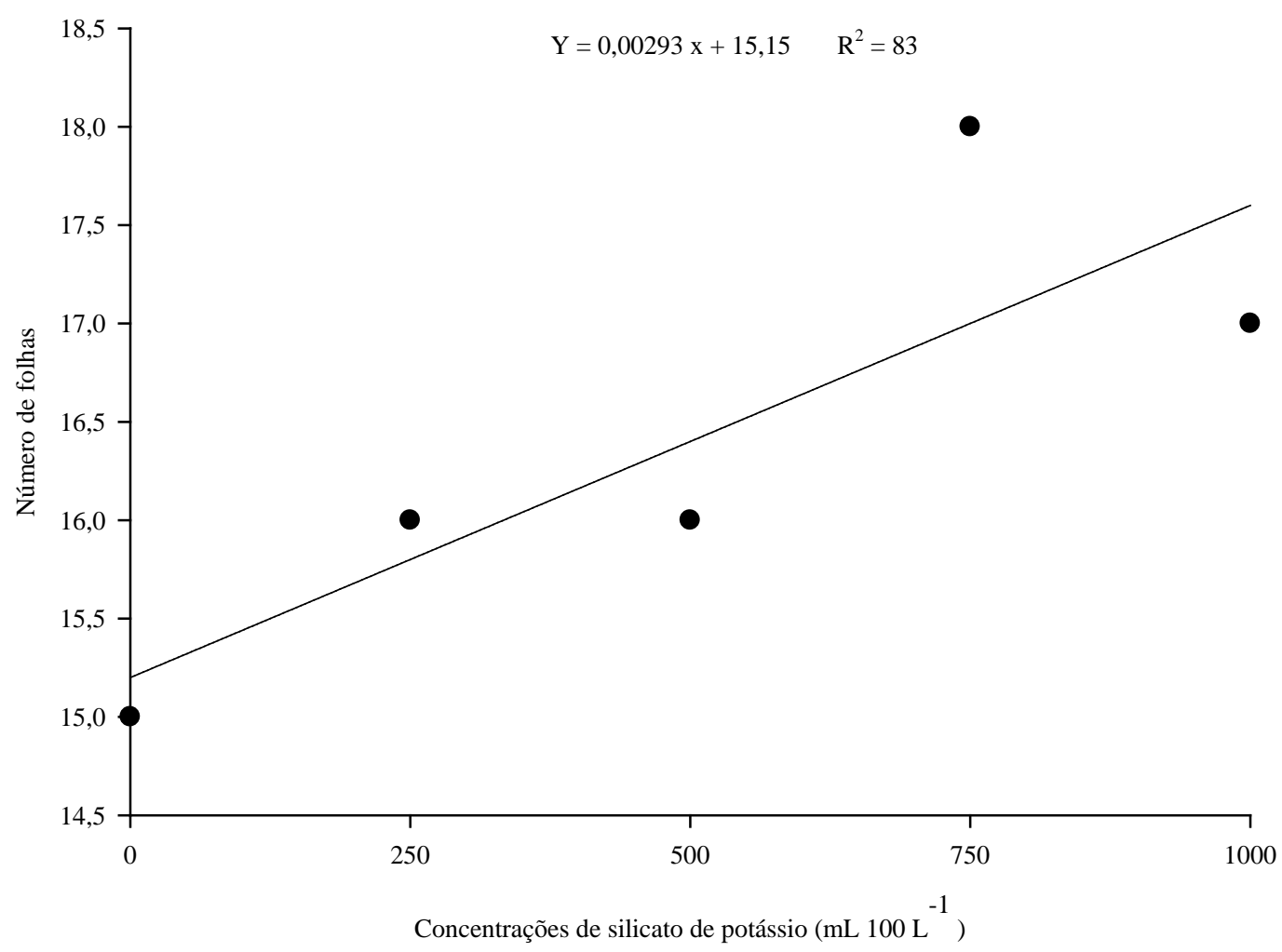

Figura 3. Número de folhas de tomateiro, aos 35 dias após o transplante, em razão da aplicação foliar de silicato de potássio.

Apesar desses resultados, constatou-se que na concentração de $1.000 \mathrm{~mL} .100 \mathrm{~L}^{-1}$ de silicato de potássio houve redução nos valores de diâmetro do colo, altura de plantas e número de folhas (Figura 1, 2 e 3). Provavelmente, o Si em concentrações altas compete com outros elementos, o que pode ter resultado o desequilíbrio nutricional. Em trigo, doses altas de silício aplicado via foliar influenciaram negativamente a taxa de transporte de elétrons, a fluorescência inicial e a fitotoxicidade (Oliveira Júnior et al., 2018). Além do Si, o produto testado possuía na sua composição potássio (K). Segundo Marschner (2012) altas concentrações de $\mathrm{K}$ podem causar desequilíbrio, reduzindo a absorção de outros nutrientes. Em bananeira, cultivada em solução nutritiva, o acréscimo de concentrações de $\mathrm{K}$, reduziu os teores foliares de nitrogênio, fósforo, magnésio, boro, cobre, zinco e manganês (Freitas et al., 2017).

\section{Conclusão}

O suprimento foliar de silicato de potássio até a concentração de 850,5, 830,3 e $750 \mathrm{~mL} .100 \mathrm{~L}^{-1}$ melhora o desenvolvimento do tomateiro, resultando em incremento do diâmetro do colo, altura de plantas e número de folhas, respectivamente. Por outro lado, na concentração de $1.000 \mathrm{~mL} .100 \mathrm{~L}^{-1}$ há redução nos valores dessas variáveis, provavelmente em razão da competição promovida pelo silício e/ou potássio.

\section{Conflito de interesses}

Os autores declaram não haver conflito de interesses. 


\section{Referências}

Alyousuf, A.; Hamid, D.; Desher, M. A.; Nikpay, A.; Laane, H. Effect of silicon fertilization on two major insect pests of tomato under greenhouse conditions. Research Square, 2021. https://doi.org/10.21203/rs.3.rs-205218/v1

Andrade, C. C. L.; Resende, R. S.; Rodrigues, F. A.; Ferraz, H. G. M.; Moreira, W. R.; Oliveira, J. R.; Mariano, R. L. R. Silicon reduces bacterial speck development on tomato leaves. Tropical Plant Pathology, v. 38, p. 436-442, 2013. https://doi.org/10.1590/S198256762013005000021

Anjos, T. V.; Tebaldi, N. D.; Mota, L. C. B. M.; Coelho, L. Silicate sources for the control of tomato bacterial spot (Xanthomonas spp.). Summa Phytopathologica, v. 40, p. 365-367, 2014. https://doi.org/10.1590/0100-5405/2007

Datnoff, L. E.; Rodrigues, F. A.; Seebolt, K. W. Silicon and plant disease. In: Datnoff L, E.; Elmer, W. H.; Huber, D. M (Eds.). Mineral nutrition and plant disease. St. Paul, MN: American Phytopathological Society, 2007. p. 233-246.

Ehret, D. L.; Menzies, J. G.; Helmera, T. Production and quality of greenhouseroses in recirculating nutrient systems. Scientia Horticulture, v. 106, p. 103-113, 2005. https://doi.org/10.1016/j.scienta.2005.03.002

Epstein, E. The anomaly of silicon in plant biology. PNAS, v. 91, p. 11-17, 1994. https://doi.org/10.1073/pnas.91.1.11

FAO - Food and Agriculture Organization of the United Nations. Faostat. 2021. Disponível em: <http://www.fao.org/faostat/en/\#home>. Acesso em: 17 maio 2021.

IBGE - Instituto Brasileiro de Engenharia e Estatística. Sistema de recuperação automática de dados-SIDRA. Banco de dados agregados. 2021. Disponível em: <http://www.sidra.ibge.gov.br/>. Acesso em: 17 maio 2021.

Ferreira, D. F. SISVAR: A computer statistical analysis system. Ciência e Agrotecnologia, v. 35, p. 1039-1042, 2011. https://doi.org/10.1590/S1413-70542011000600001

Freitas, A. S.; Pozza, E. A.; Soares, M. G. O.; Silva, H. R.; Pérez, C. D. P.; Pozza, A. A. A. Severity of yellow Sigatoka in banana cultivated in silicon nutrient solution. Australasian Plant Pathology, v. 46, p. 515-520, 2017. https://doi.org/10.1007/s13313-017-0521-0

Freitas, A. S.; Pozza, E. A. E.; Pozza, A. E. A. A.; Soares, M. G. D. O.; Silva, H. R.; Pérez, C. D. P. Interaction between potassium (K) and calcium (Ca) on the severity of Yellow Sigatoka in banana plants. African Journal of Agricultural Research, v. 12, p. 1353-1361, 2017. https://doi.org/10.5897/AJAR2017.12279

Kamenidou, S.; Cavins, T. J. Silicon supplements affect horticultural traits ofgreenhouseproduced ornamental sunflowers. Hort Science, v. 43, p. 236-239, 2008. https://doi.org/10.21273/HORTSCI.43.1.236

Marschner, H. Mineral nutrition of higher plants. 3. ed. London: Academic Press, 2012.

Neri, D. K. P.; Gomes, F. B.; Moraes, J. C.; Góes, G. B.; Marrocos, S. T. P. Influência do silício na suscetibilidade de Spodoptera frugiperda (J.E. Smith) (Lepidoptera: Noctuidae) ao inseticida lufenuron e no desenvolvimento de plantas de milho. Ciência Rural, v. 39, p. 1633-1638, 2009. https://doi.org/10.1590/S0103-84782009005000111

Nick, C.; Silva, D.; Borém, A. Tomate: do plantio à colheita. Viçosa: Editora da UFV, 2018. 
Nunes, A. M. C.; Nunes, L. R. L.; Rodrigues, A. J. O.; Uchôa, K. S. A. Silício na tolerância ao estresse hídrico em tomateiro. Revista Científica Rural, v. 21, p. 239-258, 2019. https://doi.org/10.30945/rcr-v21i2.2658

Oliveira Júnior, S. G.; Ferreira, E. A.; Nery, M. C.; Silva, R. F. C.; Melo, S. G. F.; Fialho, C. M. T. Aplicação foliar de silício em plantas de trigo associado à qualidade fisiológica de sementes. Revista Brasileira de Agropecuária Sustentável, v. 8, p.9-16, 2018. https://doi.org/10.21206/rbas.v8i1.455

Pereira, R. R. C.; Vitti, G. C.; Korndorfer, G. H. Comportamento de diferentes fontes de silício no solo e na cultura do tomateiro. Revista Brasileira de Ciência do Solo, v. 27, p. 101108, 2003. https://doi.org/10.1590/S0100-06832003000100011

Pozza, E. A.; Pozza, A. A. A.; Botelho, D. M. D. S. Silicon in plant disease control. Revista Ceres, v. 62, n. 3, p. 323-331, 2015. https://doi.org/10.1590/0034-737X201562030013

Rodrigues, A. J. O.; Nunes, L. R. L.; Nunes, A. M. C.; Uchôa, K. S. A. Efeito da adubação silicatada no cultivo de tomateiro sob estresse salino. Agropecuária Científica No Semiárido, v. 14, p. 141-148, 2019. https://doi.org/10.30969/acsa.v14i2.977

Rodrigues, C. R.; Rodrigues, T. M.; Luz, J. M. Q.; Sousa, V. B. F.; Sousa, J. B.; Nunes, A. C. P.; Trindade, P. R. Clorofila a e b de tomateiro tratado com silicato de potássio e fungicida. Global Science and Technology, v. 9, p. 54-64, 2016. https://doi.org/10.14688/19843801/gst.v9n2p54-64

Zanão Júnior, L. A.; Alvarez V, V. H.; Carvalho-Zanão, M. P.; Fontes, R. L. F.; Grossi, J. A. S. Produção de rosas influenciada pela aplicação de doses de silício no substrato. Revista $\begin{array}{lllll}\text { Brasileira de Ciência do Solo, v. 37, p.1611-1619, } 2013 . & \end{array}$ https://doi.org/10.1590/S0100-06832013000600017 